Feature Article, Instant Update

Rahel S. Ghebrihiwot ${ }^{\mathrm{a}, \mathrm{b}}$, Robert M. Kao ${ }^{\mathrm{c}}$

${ }^{a}$ Heritage University National Science Foundation Research Experiences for Undergraduates Program, USA

b Seattle University, Seattle, WA

c Associate Professor in Biology, College of Arts and Sciences, Science Department, Heritage

University, 3240 Ford Road, Toppenish, WA, 98948.

\title{
Updates on Novel SARS-CoV-2: An Emerging Coronavirus that Causes a Global Threat
}

\section{Article Info}

Keywords:

Coronavirus

Novel coronavirus

Pneumonia

SARS-CoV-2

COVID-19

Pre-symptomatic transmission

Asymptomatic transmission

Angiotensin Converting Enzyme-2

ACE-2

Pandemic

Wuhan

\begin{abstract}
The Coronavirus Disease 2019 (Covid-19) pandemic has taken center stage in infectious disease research. Since the first reports to the World Health Organization (WHO) in winter 2019, we know that the infectious agent was a virus of the coronavirus family, named SARS-CoV-2 (the severe acute respiratory syndrome coronavirus-2) causes a respiratory disease in Covid-19 and attacks lung cells due to the presence of many conserved receptor entries, namely Angiotensin Converting Enzyme-2. In our instant update review article, we highlight the prevalence and genetic diversity of bats as they are the potential natural reservoir and link SARS-CoV-2 to other coronaviruses through the circulation in bats in Southeast Asia. Furthermore, we present the
\end{abstract}


important ethical dilemmas to consider regarding human challenge studies as well as the effectiveness of herd immunity and personal protective equipment (PPE) for SARS-CoV-2. Lastly, we review the advances in the development of medical treatments and possible vaccines available to fight the virus.

\section{Introduction}

Since the winter of 2019, the rise of Covid-19 pandemic has spread across the world and affected many human lives. On March 11, 2020, the WHO named the outbreak a pandemic and now globally cases are rising sharply, outstripping the Chinese cases (Harapan, et al., 2020). As of June 28th, there are over 2.5 million confirmed cases in the U.S and over 10 million confirmed cases worldwide by the new coronavirus SARS-CoV-2, which can cause the coronavirus respiratory disease COVID-19 (CDC, 2020). As the outbreak of the disease is reaching a high number of countries all over the world, the general public awareness and scientific interest are also on the rise. Currently, the virus virulence, how it is transmitted between humans and the possible treatments of the disease are being actively studied. As there is already a lot of information available, we have here gathered the known information on the molecular organization and structure of the virus, thus creating a dynamic and scientific accurate 2D animation of SARS-CoV-2.
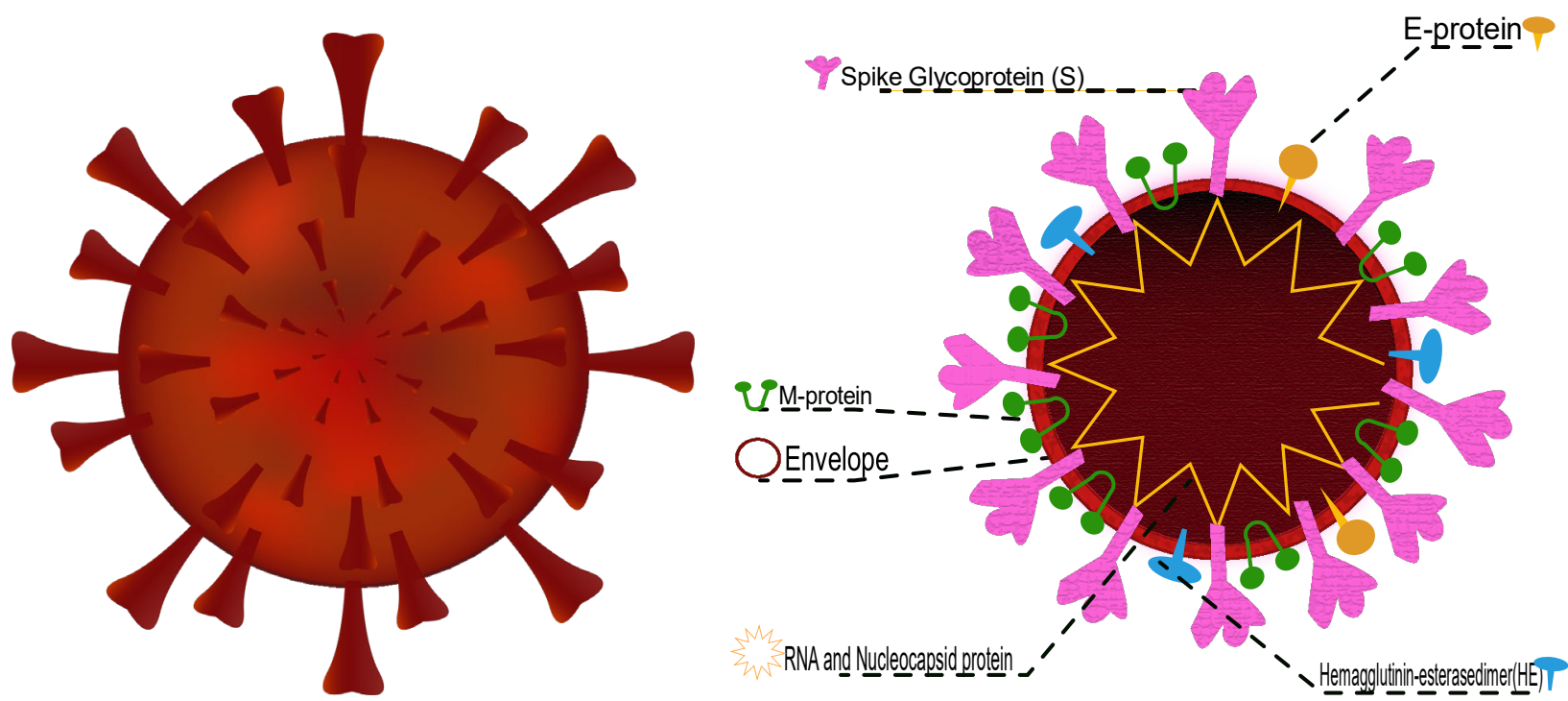

Figure 1: 2D animation showing a viral particle contains an internal helical ribonucleic acid (RNA)-protein nucleocapsid surrounded by an envelope containing viral glycoproteins.

Nucleocapsid $(\mathrm{N})$ protein is a phosphoprotein that is complexed with genome RNA to form the nucleocapsid. Spike glycoprotein (S) forms the large glycosylated peplomers that are characteristic of coronaviruses. $\mathrm{M}$, the transmembrane protein, is highly hydrophobic and spans the membrane multiple times. E, a membrane-spanning protein, is a minor component of the membrane. Some group II viruses express another glycoprotein, hemagglutinin-esterase (HE), which forms smaller spikes on virions. 
Coronaviruses--containing an RNA viral genome-- appear as spike-like protrusions creating the effect of the corona, or halo, using electron microscopes (Tyrrell and Myint, 1996). The RNA viral genome of Coronaviruses contains almost 30,000 bases long pecked together with a nucleocapsid protein into the viral particle of the aerosol. In order for Coronavirus to replicate inside host cells, it inserts its RNA viral genome into host cells and hijacks the host cellular machinery to produce new viruses. On the surface of the virion, it contains three main proteins: the envelope protein, spike protein, and hemagglutinin. These are embedded into lipid bilayer. The large spike proteins are not only responsible for the crown-like protrusions, but also recognize the corresponding receptors on the human cells called ACE-2. The protease ACE-2, mediates the cleavage of the spike-protein which then releases an epitope enabling the subsequent fusions of the virus that is present in host cytoplasm.

SARS-CoV-2 is a member of the family Coronaviridae subdivision of Betacoronavirus and orders Nidovirales. The family consists of two subfamilies: Coronavirinae and Torovirinae (Burrell, et al. 2016). In addition, the members of the subfamily Coronaviridae can be classified as the following: Alphacoronavirus, Betacoronavirus, Gammacoronavirus, and Deltacoronavirus (Burrell, et al. 2016). For instance, Alphacoronavirus contains the human coronavirus (HCoV)-229E and HCoV-NL63 (Burrell, et al. 2016). On the other hand, Betacoronavirus includes HCoV-OC43, Severe Acute Respiratory Syndrome human coronavirus (SARS-HCoV), HCoV-HKU1, and Middle Eastern respiratory syndrome coronavirus (MERS$\mathrm{CoV}$ ) with bats being the common reservoirs (Burrell, et al. 2016). In contrast to Alphacoronavirus and Betacoronavirus, the Gammacoronavirus includes viruses of whales and birds and; Deltacoronavirus includes viruses isolated from pigs and birds (Burrell, et al. 2016). SARS-CoV-2 belongs to Betacoronavirus together with two highly pathogenic viruses, SARS$\mathrm{CoV}$ and MERS-CoV. SARS-CoV-2 is an enveloped and positive-sense single-stranded RNA (+ssRNA) virus with birds being the common reservoirs responsible (Kramer, et al 2006). Some of the likely candidates for intermediate hosts include Pangolin, mink, and Rhinolophus affinis (Liu, et al.

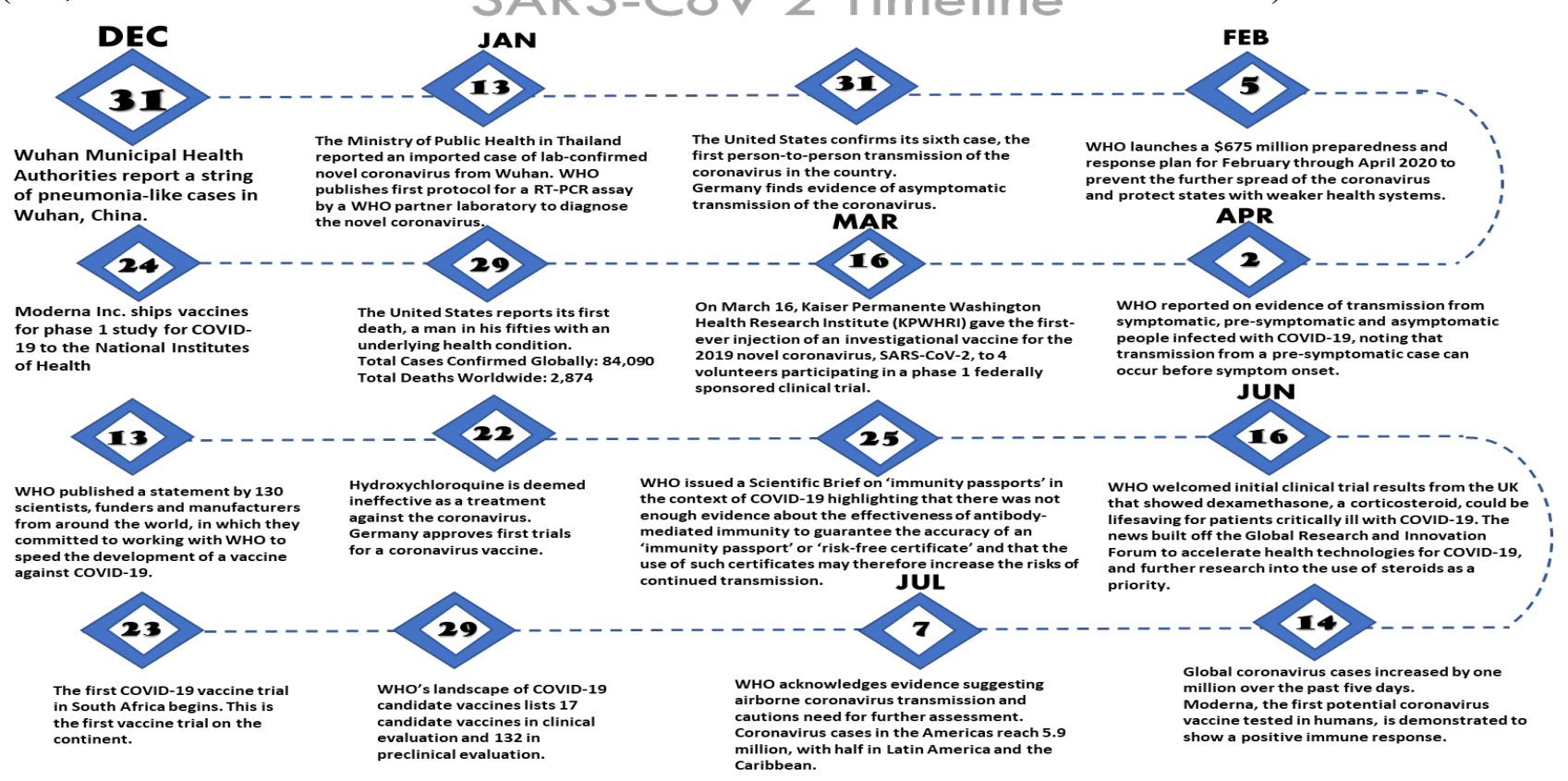


Figure 2. Timeline of the SARS CoV-2 epidemic, with the key dates noted. The blue diamond with number indicates the key highlighted events during the course of Covid-19 pandemic.

\section{The pathogen characteristics and clinical presentations of SARS-CoV-2 outbreak}

Most COVID-19 cases are mild, but severe disease can be found in any age group. Older individuals and those with underlying medical conditions are at higher risk of serious illness and death. Initial COVID-19 symptoms include fever ( $87.9 \%$ overall, but only $44 \%-52 \%$ present with fever initially), cough $(67.7 \%)$, fatigue, shortness of breath, headache, reduction in lymphocyte count (Ministério da Saúde Brasil, 2020, and WHO, 2020). Headache and diarrhea are uncommon, though lack of appetite may be an early symptom. Complications include acute respiratory distress (ARDS observed in 17-29\% of hospitalized patients, which leads to death in 4-15\% of cases), pneumonia, cardiac injury, secondary infection, kidney failure, arrhythmia, sepsis, and shock (Ministério da Saúde Brasil, 2020). Approximately 15\% of hospitalized patients were classified as severe, and approximately $5 \%$ of patients were admitted to the ICU Ministério da Saúde Brasil, 2020. Most deaths are caused by respiratory failure or respiratory failure combined with myocardial (heart) damage (WHO, 2020). The case fatality rate (CFR) depends on comorbidities; cardiovascular disease, hypertension, diabetes, and respiratory conditions all increase the CFR. Here, the CFR increases with age; individuals older than 60 are at higher risk of death, and approximately $>60 \%$ of confirmed fatalities have been male (Ministério da Saúde Brasil, 2020, and WHO, 2020). Children of all ages are susceptible to COVID-19, though generally present with milder symptoms or no symptoms at all. In the US, $34 \%$ of hospitalizations have been individuals less than 44 years old (Ministério da Saúde Brasil, 2020, and WHO, 2020). Variation in the CFR among countries may be due to demographics, testing criteria, and how COVID-19 related deaths are defined. Based on one patient, a productive immune response is generated and sustained for at least 7 days (WHO, 2020).

Recent studies have shown the role of 10 kilodaldon $(\mathrm{kDa})$ interferon-gamma-induced protein (IP-10) in short-circuit host immune system regulation. IP-10 was first identified as a chemokine secreted by neutrophils, endothelial cells, fibroblasts, astrocytes, dendritic cells, hepatocytes which are induced by IFN- $\gamma$ (a type-II IFN produced by a wide variety of lymphocyte cells) (Costela-Ruiz et al., 2020). Elevated IP-10 concentrations have been found in patients with COVID-19 mainly due to an increased secretion by infiltrating neutrophils, which induced an autocrine loop mechanism on the chemotaxis of inflamed neutrophils, leading to fulminant pulmonary inflammation [39]. This indicates a correlation with the severity and duration of acute respiratory tract infection due to viral infections (Coperchini, et al. 2020). Preliminary data indicates higher levels of IP-10 found in patients with SARS-CoV-2 and even higher levels of concentrations in patients with SARS-CoV-2 which might be linked to progression of disease severity and greater lung damage due to the activation of T-helper-1 (Th1) cell function (Coperchini, et al. 2020). Moreover, Coperchini and colleagues found an upregulation of the mouse IP-10 analogue mob-1 mRNA was observed at initiation of lung injury. Several studies also showed that the intratracheal injection of $m o b-1$ in mice induced pulmonary migration of leukocytes in the alveolar space, with massive recruitment of neutrophils, especially monocytes. These markers were predictors of the evolution of the disease towards more severe and even fatal states (Coperchini, et al. 2020). 


\section{Transmission pathway of the SARS-CoV-2 virus}

According to the CDC, as of July $19^{\text {th }}, 2020$, the pandemic COVID-19 has caused 3,698,161 infections and 139,659 deaths in 50 states and 11 territories across the U.S (CDC, 2020). Data has shown a high-quality estimates of human transmissibility $\left(\mathrm{R}_{0}\right)$ ranges from 2.2 to 3.58 (Liu, et al., 2020). It is clear now that SARS-CoV-2 can be transmitted by human-to-human despite the majority of the early cases had contact history with the Huanan Seafood market (Zheng 2020). Individuals can transmit SARS-CoV-2 to others before they have symptoms. Moreover, experiments have determined that Pre-symptomatic or asymptomatic patients can transmit SARS-CoV-2; between $12 \%$ and $23 \%$ of infections may be caused by asymptomatic or presymptomatic transmission ( $\mathrm{Du}$, et al., 2020). Models suggest up to $86 \%$ of early COVID-19 cases in China were undetected, and these infections were the source for $79 \%$ of reported cases. Behavior changes may limit spread (Johndrow, et al., 2020, Russel, et al. 2020, Silverman, et al. 2020).

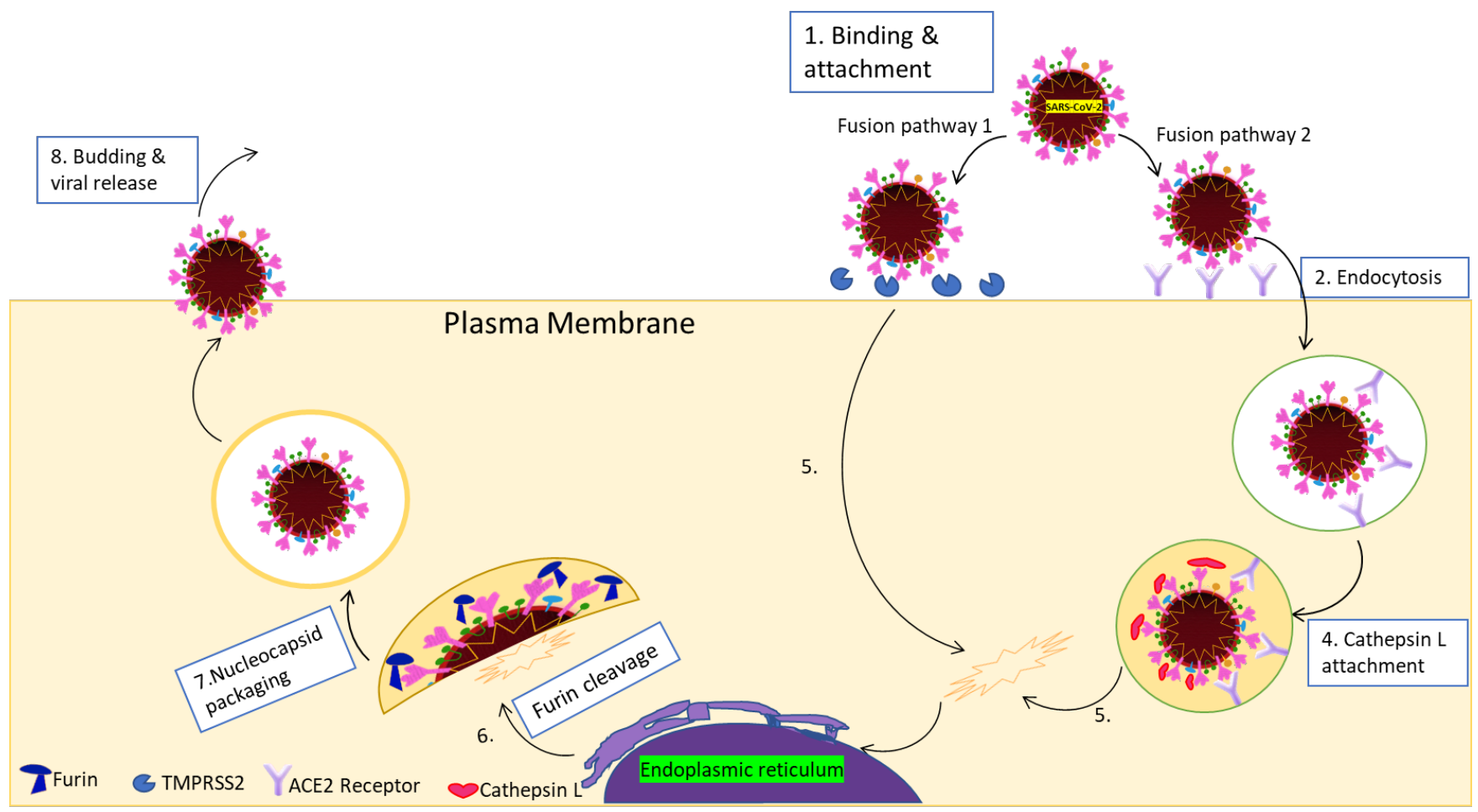

Figure 3. The schematic presentation depicts how the coronavirus attaches to the host's angiotensin converting enzyme (ACE2) cell receptor. Furthermore, it highlights the different steps in the replication, translation processes and the mechanism of the drugs that have been used recently. These important steps occur with the assistance of the host's RNA polymerase enzymes. The products are then packaged inside the cellular compartments known as the endoplasmic reticulum and the Golgi apparatus. After this process is completed, the replicated virus utilizes the vesicle trafficking system to undergo exocytosis and infect other host cells.

\section{Possible modes of respiratory virus transmission}




\section{Contact and respiratory droplets transmission}

SARS-CoV-2 is believed to spread through close contact and droplet transmission with infected people through infected secretions such as saliva, feces, lower respiratory sputum or their respiratory droplets, which are expelled when an infected person coughs, sneezes, talks or sings (Liu et al, 2020). SARS-CoV-2 replicates in the upper respiratory tract (e.g., throat), and infectious virus is detectable in throat and lung tissue for at least eight days. Respiratory droplet transmission can occur when a person is in close contact (within one meter) with an infected person who has respiratory symptoms (e.g. coughing or sneezing) or who is talking or singing; in these circumstances, respiratory droplets that include virus can reach the mouth, nose or eyes of a susceptible person and can result in infection (Chan, et al, 2020, Huang, et al, 2020, Burke et al., 2020). Indirect contact transmission involving contact of a susceptible host with a contaminated object or surface (fomite transmission) may also be possible (Liu, et al. 2020, Huang, et al. 2020, Burke et al., 2020).

\section{Airborne transmission}

It is defined as the spread of an infectious agent caused by the dissemination of droplet nuclei (aerosols) that remain infectious when suspended in air over long distances and time (WHO, 2014). Transmission occurs via the dissemination of microorganisms by aerosolization during medical procedures (WHO, 2020). Aerosolized virus has been detected in COVID-19 patient rooms, with particle sizes within the human respirable range $(0.25-2.5 \mu \mathrm{m})$ (Liu et al., 2020). Organisms are contained in droplet nuclei (airborne particles less than $5 \mu \mathrm{m}$ that result from the evaporation of large droplets) that remain suspended in the air for long periods of time to be inhaled deep into the lung, which causes infection in the alveolar tissues of the lower respiratory tract (Pepper and Gerba, 2015). Conversely, there have been some other postulations, indicating that aerodynamic diameter of $20 \mu \mathrm{m}$ or $10 \mu \mathrm{m}$ or less should be reckoned to be aerosols, based on their ability to linger in the air for a prolonged period, and their ability to reach the alveolar region of the lung (Pepper and Gerba, 2015). WHO acknowledges airborne transmission of SARS-CoV-2 in closed settings and the possibility that SARS-CoV-2 may be transmitted by aerosols (so-called airborne transmission) even in the absence of aerosol-generating procedures (such as intubation or noninvasive positive pressure ventilation) (WHO, 2020). Control of airborne transmission is the most difficult because it requires control of airflow through special ventilation systems (WHO, 2020).

\section{Fomite transmission}

Respiratory secretions or droplets expelled by infected individuals can contaminate surfaces and objects, creating fomites (contaminated surfaces) (Van Doremalen, et al, 2020). Transmission occurs via indirectly through touching surfaces in the immediate environment or objects contaminated with virus from an infected person (e.g. stethoscope or thermometer), followed by touching the mouth, nose, or eyes (Chia, et al. 2020). There are no specific reports which have directly demonstrated fomite transmission. A recent commentary in The Lancet entitled, Exaggerated risk of transmission of COVID-19 by fomites, have suggested that based on the biology of the virus, lab testing and the patterns of spread, fomites do not seem to be a major concern [40]. However, other studies think that fomite transmission is considered a likely mode of transmission for SARS-CoV-2, given consistent findings about environmental contamination 
in the vicinity of infected cases and the fact that other coronaviruses and respiratory viruses can transmit this way (Guo, et al. 2020). More studies need to be conducted to clarify fomite transmission of SARS-CoV-2 and additional SARS-CoV-2 mutations in the future to safeguard public and global health policies.

\section{Highlights the ethical analysis of SARS-CoV-2: human challenge studies}

Human challenge studies involve the intentional infection of research participants and can provide a powerful scientific method for the testing of vaccines and therapeutics and for studying host-pathogen interactions in small numbers of participants (ie, around 25-100 people) (Callow, et al., 1990).. Such studies have been done with many pathogens, including low virulence coronavirus strains and pandemic influenza virus H1N1 (Callow, et al., 1990). Challenge studies generally have a good safety record; however, there have been rare cases of serious harms, such as myocarditis among influenza challenge study participants (Higgins, et al. 1983). Welldesigned human challenge studies have the potential to improve the efficiency of vaccine development (Higgins, et al. 1983, Tyrrell, 1979). These studies also highlight the importance of ethical dimensions and informed consent of patients participating in the human challenge studies.

Numerous clinical trials to evaluate novel vaccine candidates and drug repurposing strategies for the prevention and treatment of SARS-CoV-2 infection are currently ongoing. However, it is unknown whether these trials will produce effective interventions. In addition, it is unclear how long these studies will take to establish efficacy and safety, although an optimistic estimate for any vaccine trial is at least 12-18 months (Randolph, et al. 2020). In the absence of a vaccine, building up SARS-CoV-2 herd immunity through natural infection is theoretically possible (Randolph, et al. 2020). However, there is no straightforward, ethical path to reach this goal, as the societal consequences of achieving it are devastating (Randolph, et al. 2020). Herd immunity can be reached when a sufficient number of people in the population have recovered from a disease and have developed antibodies against future infection. A major problem with relying on community infection to create herd immunity to the virus that causes COVID-19 is that it is not yet clear whether infection with the COVID-19 virus makes a person immune to future infection (Randolph, et al. 2020). Findings from a recent study published in The New England Journal of Medicine "raise concern" that humoral immunity against SARS-CoV-2 may not be long lasting in persons with mild illness. Furthermore, the authors mentioned that their study had a majority of patients living with symptoms of COVID-19 (Cavalcanti, et al., 2020). They used enzymelinked immunosorbent assay (ELISA) to quantify the anti-SARS-CoV-2 receptor-binding domain (RBD) serum IgG concentrations of the participants as equivalent binding activity to a concentration of a control anti-receptor-binding domain monoclonal IgG (Cavalcanti, et al., 2020). The results suggest that antibody loss was quicker than the reported for SARS-CoV-1. This warrants future studies to define quantitative protection threshold on the role of antibodies against SARS-CoV-2 which are important for herd immunity, vaccine durability, immunity passports especially in short lived immunity (Cavalcanti, et al., 2020).

Another topic that needs to be addressed is the effectiveness of PPE for SARS-CoV-2 is currently unknown, and data from other related coronaviruses are used for guidance. It can be 
noted that healthcare workers are at high risk of acquiring COVID-19, even with recommended PPE (WHO, 2020). WHO indicates healthcare workers should wear clean long-sleeve gowns as well as gloves (WHO, 2020). The use of facemasks is crucial for health workers and people in close contact with infected patients (at home or in a healthcare facility) (WHO, 2020). Respirators (NIOSH-certified N95, EUFFP2 or equivalent) are recommended for those dealing with possible aerosols. Additional protection, such as a Powered Air Purifying Respirator (PAPR) with a full hood, should be considered for high-risk procedures (i.e., intubation, ventilation) (WHO, 2020).

\section{Prevalence and Genetic Diversity of Coronaviruses in Bats}

Modeling between SARS-CoV-2 Spike and ACE2 proteins suggests that SARS-CoV-2 can bind and infect a variety of animals including bat, civet, monkey, swine cells and humans. The outbreak of severe acute respiratory syndrome (SARS) and the recent identification of new coronaviruses have highlighted the necessity for further investigation of coronavirus ecology, in particular the role of bats and other wild animals Tang, et al. (2006). Bats are found to the reservoir of a wide variety of coronaviruses, including severe acute respiratory syndrome coronavirus SARS-CoV -like viruses Tang, et al. (2006). Large population sizes and densities, and the ability to migrate, bats appear to be ideal candidates for the natural reservoirs of all coronaviruses Tang, et al. (2006). Recent studies have suggested Pangolin and Mink as possible natural reservoirs of SARS-CoV-2 viruses while Masked palm civets (Paguma larvata spp.) are the intermediate host Tang, et al. (2006). To determine the overall diversity of coronaviruses that were isolated from bats, preliminary phylogenetic analysis of the RNA-dependent RNA Polymerase (RdRp) fragment obtained from Reverse Transcriptase-Polymerase Chain Reaction (RT-PCR) detection revealed that all viruses characterized fell within the previously recognized coronavirus groups, including the SARS-CoV group which is further summarized below (Table $1)$.

\section{Development of medical treatments and vaccines for SARS-CoV-2 infection}

Currently, the treatment of patients with COVID-19 is mainly supportive care and symptomatic, including ventilation, oxygen therapy, antibiotic treatment, and antifungal treatment, and extra-corporeal membrane oxygenation (ECMO). A number of therapeutics to develop a SARS-CoV-2 vaccine in human and animal trials are ongoing, but no preliminary results are available (Chen, et al., 2020). Preliminary data evaluated the effectiveness of several common antiviral drugs in treating SARS-CoV-2 infection, namely, Corticosteroids, Hydroxychloroquine, chloroquine, azithromycin, tocilizumab, Intravenous immunoglobulin (IVIg) and favipiravir (T-750) against the infection of SARS-CoV-2 on Vero E6 cells in vitro (Wang, et al. 2020). Preliminary reports from several clinical trials in China suggest that favipiravir improves lung function and reduces recovery time in COVID-19 patients. Moreover, early results suggest that tocilizumab may be effective at treating severe COVID-19 cases (Sheahan, et al., 2017). Remdesivir has been reported as a promising antiviral drug against a wide array of RNA viruses (Savarino, et al, 2006). 
Meanwhile, some evidence suggests that chloroquine is effective at reducing symptom duration (NIH, US Department of Health and Human Services, 2020). Among these drugs, hydroxychloroquine was found to have no benefits for patients with mild COVID-19 given risk of adverse effects on heart function supported by the NEJM data (Dall, 2020). A research done in the University of Minnesota showed that, among the 423 participants who provided data, hydroxychloroquine failed to cause a statistically significant difference in symptom severity or prevalence over the 14-day period (Dall, 2020). However, dexamethasone reduced deaths by $36 \%$ compared with usual care in patients needing mechanical ventilation (Dall, 2020). In patients receiving oxygen, the incidence of death was $18 \%$ lower for patients on dexamethasone (Dall, 2020). Intravenous immunoglobulin (IVIg) may be effective at inhibiting deterioration when given at the appropriate time in severe cases (Huang, et al., 2013). Corticosteroids are commonly given to COVID-19 patients at risk of ARDS, but their use is not recommended by the US CDC (Huang, et al., 2013).

At present, scientists have been primarily working on developing a vaccine for SARSCoV-2. To search for an anti-viral effective vaccine in treating SARS-CoV-2 infection, John Hopkins University is pursuing an Investigational New Drug (IND) approval to provide passive antibody therapy (convalescent serum) to patients, and Takeda Pharma (Japan) is working to create treatments based on patient plasma. multiple entities are working on phase 1 clinical trial evaluating an investigational vaccine designed to protect against coronavirus disease 2019 (COVID-19) including Kaiser Permanente, funded by NIH/NIAID, Moderna Therapeutics and Gilead Sciences, and Sanofi with HHS (The Bio Connection, 2020). Moderna has been working on phase 1 clinical vaccine trials in humans in Washington state since March $16^{\text {th }}, 2020$, and results in published Phase 1 study shows 'promising' safety and immune response (Coperchini, et al. 2020). These early results, published in the New England Journal of Medicine, showed that the vaccine worked to trigger an immune response with mild side effects -- fatigue, chills, headache, muscle pain, pain at the injection site -- becoming the first US vaccine candidate to publish results in a peer-reviewed medical journal (Coperchini, et al. 2020). They are currently working on phase 3 study which results from phase 1 study can help guide what it will look like (Coperchini, et al. 2020). In addition to Moderna, recent publication in the Lancet from University of Oxford suggest a phase 1 trial with CanSino Biologics' (Tianjin, China) adenovirus type-5 (Ad5)-vectored COVID-19 vaccine has moved into working on their phase 2 trial in Wuhan (Hubei province, China) aiming to assess the immunogenicity and the right vaccine dose in larger population (Zhu, et al., 2020). The results support testing of the Ad5-vectored COVID19 vaccine at $5 \times 10^{10}$ viral particles in a phase 3 effectiveness trial in healthy adults, making it a potential candidate for emergency vaccination of acute protective response (Zhu, et al., 2020).

\section{Concluding remarks}

SARS-CoV-2 is an emerging pathogen, without any effective drug available for treatment at the moment. It spreads quickly and can result in death of the infected patients. Effective preventive measures must be implemented to control it from global spreading. In addition, great effort should be made on the development of vaccine and antiviral drugs. Furthermore, more research into SARS-CoV-2 molecular mechanisms for host immune-evasion and infectivity deserve future investigation. Meanwhile, the intermediate host and the molecular mechanism of its cross-species spread should be further investigated. Legislation should be employed to 
prohibit the trade of wild animals, the potential intermediate host(s) of various viruses, to prevent the outbreak of this and other novel viruses in future.

\section{Acknowledgements:}

We thank anonymous reviewers for their comments and suggestions. We also like to acknowledge support from NSF Division of Biological Infrastructure (DBI) BIO \#1852032.

\section{Figure Legends:}

Figure 1: 2D animation showing a viral particle contains an internal helical ribonucleic acid (RNA)-protein nucleocapsid surrounded by an envelope containing viral glycoproteins. Nucleocapsid (N) protein is a phosphoprotein that is complexed with genome RNA to form the nucleocapsid. Spike glycoprotein (S) forms the large glycosylated peplomers that are characteristic of coronaviruses. $\mathrm{M}$, the transmembrane protein, is highly hydrophobic and spans the membrane multiple times. E, a membrane-spanning protein, is a minor component of the membrane. Some group II viruses express another glycoprotein, hemagglutinin-esterase (HE), which forms smaller spikes on virions.

Figure 2: Timeline of key events during Covid-19 pandemic.

Figure 3. The schematic presentation depicts how the coronavirus attaches to the host's angiotensin converting enzyme (ACE2) cell receptor. Furthermore, it highlights the different steps in the replication, translation processes and the mechanism of the drugs that have been used recently. These important steps occur with the assistance of the host's RNA polymerase enzymes. The products are then packaged inside the cellular compartments known as the endoplasmic reticulum and the Golgi apparatus. After this process is completed, the replicated virus utilizes the vesicle trafficking system to undergo exocytosis and infect other host cells.

Table 1. Summary of groups, abbreviations, and name for each of the coronaviruses based on genetic analysis and phylogenetic trees

\section{References}

1. Harapan, H., Itoh, N., Yufika, A., Winardi, W., Keam, S., Te, H., Megawati, D., Hayati, Z., Wagner, A. L., \& Mudatsir, M. (2020). Coronavirus disease 2019 (COVID-19): A literature review. Journal of infection and public health, 13(5), 667-673. https://doi.org/10.1016/j.jiph.2020.03.019

2. "Cases in the U.S." Centers for Disease Control and Prevention, Centers for Disease Control and Prevention, 11 June 2020, www.cdc.gov/coronavirus/2019-ncov/casesupdates/cases-in-us.html. 
3. Tyrrell, David A. J., and Myint, Steven H. "Coronaviruses." In Medical Microbiology, edited by Baron S, Galveston, TX: University of Texas Medical Branch at Galveston, 1996.

4. Burrell C., Howard C., Murphy F. 5th ed. Academic Press; United States: 2016. Fenner and White's medical virology.

5. Kramer A., Schwebke I., Kampf G. How long do nosocomial pathogens persist on inanimate surfaces? A systematic review. BMC Infect Dis. 2006;6:130.

6. Liu, Ping, et al. "Are Pangolins the Intermediate Host of the 2019 Novel Coronavirus (SARS-CoV-2)?" PLOS Pathogens, Public Library of Science, 2020, journals.plos.org/plospathogens/article?id=10.1371\%2Fjournal.ppat.1008421.

7. Brasil. Ministério da Saúde. Protocolo de manejo clínico para o novo-coronavírus (2019nCoV). [cited 2020 Feb 12]. Available

from: https://portalarquivos2.saude.gov.br/images/pdf/2020/fevereiro/11/protocolo -manejo-coronavirus.pdf.

8. Report of the WHO-China Joint Mission on Coronavirus Disease 2019 (COVID-19). [cited 2020 Feb 25]. Available from: https://www.who.int/docs/defaultsource/coronaviruse/who-china-joint-mission-on-covid-19-final-report.pdf.

9. Liu, Y., Gayle, A. A., Wilder-Smith, A., \& Rocklöv, J. (2020). The reproductive number of COVID-19 is higher compared to SARS coronavirus. Journal of travel medicine, 27(2), taaa021. https://doi.org/10.1093/jtm/taaa021

10. Zheng, Jun. "SARS-CoV-2: an Emerging Coronavirus That Causes a Global Threat." International Journal of Biological Sciences, Ivyspring International Publisher, 15 Mar. 2020, www.ncbi.nlm.nih.gov/pmc/articles/PMC7098030/\#B11.

11. Du, Z.; Xu, X.; Wu, Y.; Wang, L.; Cowling, B. J.; Meyers, L. A., The serial interval of COVID-19 from publicly reported confirmed cases. medRxiv 2020, 2020.02.19.20025452. https://www.medrxiv.org/content/medrxiv/early/2020/03/13/2020.02.19.20025452.full.pd $\mathrm{f}$

12. Johndrow, J. E.; Lum, K.; Ball, P., Estimating SARS-CoV-2-positive Americans using deaths-only data. arXiv preprint arXiv:2004.02605 2020.

13. Russell, T. W.; Hellewell, J.; Abbott, S.; Golding, N.; Gibbs, H.; Jarvis, C. I.; van Zandvoort, K.; group, C. n. w.; Flasche, S.; Eggo, R. M.; Edmunds, W. J.; Kucharski, A. J., Using a delay-adjusted case fatality ratio to estimate under-reporting. CMMID: 2020.

14. Silverman, J. D.; Hupert, N.; Washburne, A. D., Using influenza surveillance networks to estimate state-specific prevalence of SARS-CoV-2 in the United States. Science Translational Medicine 2020, eabc1126.

15. Liu J, Liao X, Qian S, Yuan J, Wang F, Liu Y, et al. Community Transmission of Severe Acute Respiratory Syndrome Coronavirus 2, Shenzhen, China, 2020. Emerg Infect Dis. 2020;26:1320-3.

16. Chan JF-W, Yuan S, Kok K-H, To KK-W, Chu H, Yang J, et al. A familial cluster of pneumonia associated with the 2019 novel coronavirus indicating person-to-person transmission: a study of a family cluster. Lancet. 2020;395 14-23. 
17. Huang C, Wang Y, Li X, Ren L, Zhao J, Hu Y, et al. Clinical features of patients infected with 2019 novel coronavirus in Wuhan, China. Lancet. 2020;395:497-506.

18. Burke RM, Midgley CM, Dratch A, Fenstersheib M, Haupt T, Holshue M, et al. Active Monitoring of Persons Exposed to Patients with Confirmed COVID-19 - United States, January-February 2020. MMWR Morb Mortal Wkly Rep. 2020;69(:245-6.

19. Infection Prevention and Control of Epidemic-and Pandemic-prone Acute Respiratory Infections in Health Care. Geneva: World Health Organization; 2014 (available at https://apps.who.int/iris/bitstream/handle/10665/112656/9789241507134_eng.pdf;jsessio nid=41 AA684FB64571CE8D8A453C4F2B2096? sequence=1).

20. Advice on the use of masks in the context of COVID-19. Interim guidance. Geneva: World Health Organization; 2020 (available at https://www.who.int/publications/i/item/advice-on-the-use-of-masks-in-thecommunity-during-home-care-and-in-healthcare-settings-in-the-context-of-the-novelcoronavirus-(2019-ncov)-outbreak).

21. Liu, Y.; Ning, Z.; Chen, Y.; Guo, M.; Liu, Y.; Gali, N. K.; Sun, L.; Duan, Y.; Cai, J.; Westerdahl, D.; Liu, X.; Ho, K.-f.; Kan, H.; Fu, Q.; Lan, K., Aerodynamic Characteristics and RNA Concentration of SARS-CoV-2 Aerosol in Wuhan Hospitals during COVID-19 Outbreak. bioRxiv 2020, 2020.03.08.982637. https://www.biorxiv.org/content/biorxiv/early/2020/03/10/2020.03.08.982637.full.pdf

22. Pepper, I. L., \& Gerba, C. P. (2015). Aeromicrobiology. Environmental Microbiology, 89-110. https://doi.org/10.1016/B978-0-12-394626-3.00005-3

23. Van Doremalen N, Bushmaker T, Morris DH, Holbrook MG, Gamble A, Williamson $\mathrm{BN}$, et al. Aerosol and surface stability of SARS-CoV-2 as compared with SARS-CoV-1. N Engl J Med. 2020;382:1564-7.

24. Chia PY, for the Singapore Novel Coronavirus Outbreak Research T, Coleman KK, Tan YK, Ong SWX, Gum M, et al. Detection of air and surface contamination by SARSCoV-2 in hospital rooms of infected patients. Nat Comm. 2020;11(1).

25. Guo Z-D, Wang Z-Y, Zhang S-F, Li X, Li L, Li C, et al. Aerosol and Surface Distribution of Severe Acute Respiratory Syndrome Coronavirus 2 in Hospital Wards, Wuhan, China, 2020. Emerg Infect Dis. 2020;26(7).

26. Callow KA, Parry HF, Sergeant M, Tyrrell DA. The time course of the immune response to experimental coronavirus infection of man. Epidemiol Infect. 1990;105:435-446. [PMC free article] [PubMed] [Google Scholar]

27. Higgins PG, Phillpotts RJ, Scott GM, Wallace J, Bernhardt LL, Tyrrell DA. Intranasal interferon as protection against experimental respiratory coronavirus infection in volunteers. Antimicrob Agents Chemother. 1983;24:713-715. [PMC free article] [PubMed] [Google Scholar]

28. Tyrrell DA. Studies of rhinoviruses and coronaviruses at the Common Cold Unit, Salisbury, Wiltshire. Postgrad Med J. 1979;55:117-121. [PMC free article] [PubMed] [Google Scholar]

29. Randolph, H. E., \& Barreiro, L. B. (2020). Herd Immunity: Understanding COVID-19. Immunity, 52(5), 737-741. https://doi.org/10.1016/j.immuni.2020.04.012 
30. WHO, Infection prevention and control during health care when novel coronavirus (nCoV) infection is suspected; 2020. https://www.who.int/publications-detail/infectionprevention-and-controlduring-health-care-when-novel-coronavirus-(ncov)-infection-issuspected-20200125

31. Tang, X. C., Zhang, J. X., Zhang, S. Y., Wang, P., Fan, X. H., Li, L. F., Li, G., Dong, B. Q., Liu, W., Cheung, C. L., Xu, K. M., Song, W. J., Vijaykrishna, D., Poon, L. L., Peiris, J. S., Smith, G. J., Chen, H., \& Guan, Y. (2006). Prevalence and genetic diversity of coronaviruses in bats from China. Journal of virology, 80(15), 7481-7490. https://doi.org/10.1128/JVI.00697-06

32. Chen N, Zhou M, Dong X, Qu J, Gong F, Han Y. et al. Epidemiological and clinical characteristics of 99 cases of 2019 novel coronavirus pneumonia in Wuhan, China: a descriptive study. Lancet. 2020;395:507-13. [PMC free article] [PubMed] [Google Scholar]

33. Holshue ML, DeBolt C, Lindquist S, Lofy KH, Wiesman J, Bruce H. et al. First Case of 2019 Novel Coronavirus in the United States. N Engl J Med. 2020 [Epub ahead of print]

34. Wang M, Cao R, Zhang L, Yang X, Liu J, Xu M. et al. Remdesivir and chloroquine effectively inhibit the recently emerged novel coronavirus (2019-nCoV) in vitro. Cell Res. 2020

35. Sheahan TP, Sims AC, Graham RL, Menachery VD, Gralinski LE, Case JB, Broadspectrum antiviral GS-5734 inhibits both epidemic and zoonotic coronaviruses. Sci Transl Med. 2017. 9.

36. Savarino A, Di Trani L, Donatelli I, Cauda R, Cassone A. New insights into the antiviral effects of chloroquine. Lancet Infect Dis. 2006;6:67-9.

37. "NIH Clinical Trial of Investigational Vaccine for COVID-19 Begins." National Institutes of Health, U.S. Department of Health and Human Services, 16 Mar. 2020, www.nih.gov/news-events/news-releases/nih-clinical-trial-investigational-vaccine-covid19-begins.

38. Reports, Staff. "Moderna's Coronavirus Vaccine Shows 'Promising' Safety and Immune Response Results in Published Phase 1 Study." THE BIO CONNECTION, THE BIO CONNECTION - Http://Thebioconnection.com, 15 July 2020, thebioconnection.com/modernas-coronavirus-vaccine-shows-promising-safety-andimmune-response-results-in-published-phase-1-study/.

39. Coperchini, F., Chiovato, L., Croce, L., Magri, F., \& Rotondi, M. (2020). The cytokine storm in COVID-19: An overview of the involvement of the chemokine/chemokinereceptor system. Cytokine \& growth factor reviews, 53, 25-32. https://doi.org/10.1016/j.cytogfr.2020.05.003

40. Costela-Ruiz, Víctor J., et al. "SARS-CoV-2 Infection: The Role of Cytokines in COVID-19 Disease." Cytokine \& Growth Factor Reviews, Pergamon, 2 June 2020, www.sciencedirect.com/science/article/pii/S135961012030109X?via\%3Dihub.

41. Goldman E. (2020). Exaggerated risk of transmission of COVID-19 by fomites. The Lancet. Infectious diseases, S1473-3099(20)30561-2. Advance online publication. https://doi.org/10.1016/S1473-3099(20)30561-2 
42. Cavalcanti, A.B. et al., "Rapid Decay of Anti-SARS-CoV-2 Antibodies in Persons with Mild Covid-19: NEJM.” New England Journal of Medicine, 23 July 2020, www.nejm.org/doi/full/10.1056/NEJMc2025179?query=RP.

43. Zhu, F., Guan, X., Li, Y. et al. Immunogenicity and safety of a recombinant adenovirus type-5-vectored COVID-19 vaccine in healthy adults aged 18 years or older: a randomised, double-blind, placebo-controlled, phase 2 trial. (2020). https://doi.org/10.1016/S0140-6736(20)31605-6

44. Dall, Chris. "Hydroxychloroquine Versus COVID-19: A Rapid Systematic Review and Meta-Analysis." 17 July 2020, doi:10.37473/dac/10.1101/2020.04.14.20065276.

45. Huang, Alina M, et al. "Intravenous Immune Globulin." SpringerReference, 15 Nov. 2013, doi:10.1007/springerreference_38798.

46. Zhang, F., Luo, S., Gu, J. et al. Prevalence and phylogenetic analysis of porcine diarrhea associated viruses in southern China from 2012 to 2018. BMC Vet Res 15, 470 (2019). https://doi.org/10.1186/s12917-019-2212-2

47. Morgat A, Lombardot T, Coudert E, Axelsen K, Neto TB, Gehant S, Bansal P, Bolleman J, Gasteiger E, de Castro E, Baratin D, Pozzato M, Xenarios I, Poux S, Redaschi N, Bridge A, UniProt Consortium.

48. Ontiveros, E., Kim, T. S., Gallagher, T. M., \& Perlman, S. (2003). Enhanced virulence mediated by the murine coronavirus, mouse hepatitis virus strain JHM, is associated with a glycine at residue 310 of the spike glycoprotein. Journal of virology, 77(19), 1026010269. https://doi.org/10.1128/jvi.77.19.10260-10269.2003

49. Li W, Shi Z, Yu M, Ren W, Smith C, Epstein JH, Bats are natural reservoirs of SARS-like coronaviruses. Science. 2005;310:676-9.

50. Tang, X.C.; Zhang, J.X.; Zhang, S.Y.; Wang, P.; Fan, X.H.; Li, L.F.; Li, G.; Dong, B.Q.; Liu, W.; Cheung, C.L.;et al. Prevalence and genetic diversity of coronaviruses in bats from China. J. Virol. 2006, 80, 7481-7490.

51. Menachery, Vineet D., et al. "SARS-like WIV1-CoV Poised for Human Emergence." PNAS, National Academy of Sciences, 15 Mar. 2016, www.pnas.org/content/113/11/3048.

52. Yu-Ching Lan, Tze-Tze Liu, Jyh-Yuan Yang, Cheng-Ming Lee, Yen-Ju Chen, Yu-Jiun Chan, Jang-Jih Lu, Hsin-Fu Liu, Chao A. Hsiung, Mei-Shang Ho, Kwang-Jen Hsiao, Hour-Young Chen, Yi-Ming Arthur Chen, Molecular Epidemiology of Severe Acute Respiratory Syndrome-Associated Coronavirus Infections in Taiwan, The Journal of Infectious Diseases, Volume 191, Issue 9, 1 May 2005, Pages 1478-1489, https://doi.org/10.1086/428591

53. Sarma, Jayasri Das, et al. "Mouse Hepatitis Virus Type-2 Infection in Mice: An Experimental Model System of Acute Meningitis and Hepatitis." Experimental and Molecular Pathology, Academic Press, 25 May 2002, www.sciencedirect.com/science/article/abs/pii/S0014480001923780?via\%3Dihub.

54. Sun, L., Zhang, G. H., Jiang, J. W., Fu, J. D., Ren, T., Cao, W. S., Xin, C. A., Liao, M., \& Liu, W. J. (2007). A Massachusetts prototype like coronavirus isolated from wild peafowls is pathogenic to chickens. Virus research, 130(1-2), 121-128. https://doi.org/10.1016/j.virusres.2007.06.003 
55. Liu S, Chen J, Chen J, et al. Isolation of avian infectious bronchitis coronavirus from domestic peafowl (Pavo cristatus) and teal (Anas). J Gen Virol. 2005;86(Pt 3):719-725. doi:10.1099/vir.0.80546

56. Lau SKP, Woo PCY, Li KSM, Huang Y, Tsoi HW, Wong BHL, Severe acute respiratory syndrome coronavirus-like virus in Chinese horseshoe bats. Proc Natl Acad Sci U S A. 2005;102:14040-5.

57. Woo PC, Lau SK, Li KS, Poon RW, Wong BH, Tsoi HW, Molecular diversity of coronaviruses in bats. Virology. 2006;351:180-7.

58. Wu, Donglai, et al. "Civets Are Equally Susceptible to Experimental Infection by Two Different Severe Acute Respiratory Syndrome Coronavirus Isolates." Journal of Virology, American Society for Microbiology Journals, 15 Feb. 2005, jvi.asm.org/content/79/4/2620.

59. Qu, D., Zheng, B., Yao, X., Guan, Y., Yuan, Z. H., Zhong, N. S., Lu, L. W., Xie, J. P., \& Wen, Y. M. (2005). Intranasal immunization with inactivated SARS-CoV (SARSassociated coronavirus) induced local and serum antibodies in mice. Vaccine, 23(7), 924931. https://doi.org/10.1016/j.vaccine.2004.07.031

60. Hu, Z., \& Shi, Z. (2008). Investigation of Animal Reservoir(s) of SARS-CoV. Emerging Infections in Asia, 57-73. https://doi.org/10.1007/978-0-387-75722-3_4

61. Armesto M, Evans S, Cavanagh D, Abu-Median A-B, Keep S, Britton P (2011) A Recombinant Avian Infectious Bronchitis Virus Expressing a Heterologous Spike Gene Belonging to the 4/91 Serotype. PLoS ONE 6(8): e24352. https://doi.org/10.1371/journal.pone.0024352

62. Lavi, E., Suzumura, A., Hirayama, M., Highkin, M. K., Dambach, D. M., Silberberg, D. H., \& Weiss, S. R. (1987). Coronavirus mouse hepatitis virus (MHV)-A59 causes a persistent, productive infection in primary glial cell cultures. Microbial pathogenesis, 3(2), 79-86. https://doi.org/10.1016/0882-4010(87)90066-0

63. Mondal SP, Cardona CJ. Genotypic and phenotypic characterization of the California 99 (Ca199) variant of infectious bronchitis virus. Virus Genes. 2007;34(3):327-341. doi:10.1007/s11262-006-0014-7

64. Yang, J. T., \& Ma, B. C. (2013). Complete genome sequence of a nephropathogenic infectious bronchitis virus strain isolated in china. Genome announcements, 1(5), e00815-13. https://doi.org/10.1128/genomeA.00815-13

65. Lau, S. K. P.; Woo, P. C. Y.; Yip, C. C. Y.; Tse, H.; Tsoi, H.-w.; Cheng, V. C. C.; Lee, P.; Tang, B. S. F.; Cheung, C. H. Y.; Lee, R. A.; So, L.-y.; Lau, Y.-1.; Chan, K.-h.; Yuen, K.-y. (2006). "Coronavirus HKU1 and Other Coronavirus Infections in Hong Kong". Journal of Clinical Microbiology. 44 (6): 2063-71. doi:10.1128/JCM.02614-05. PMC 1489438. PMID 16757599.

66. Lim, Yvonne Xinyi; Ng, Yan Ling; Tam, James P.; Liu, Ding Xiang (2016-07-25). "Human Coronaviruses: A Review of Virus-Host Interactions". Diseases. 4 (3): 26. doi:10.3390/diseases4030026. ISSN 2079-9721. PMC 5456285. PMID 28933406. See Table 1.

67. Woo, Patrick C. Y.; Huang, Yi; Lau, Susanna K. P.; Yuen, Kwok-Yung (2010-08-24). "Coronavirus Genomics and Bioinformatics Analysis". Viruses. 2 (8): 1804-1820. 
doi:10.3390/v2081803. ISSN 1999-4915. PMC 3185738. PMID 21994708. In all members of Betacoronavirus subgroup A, a haemagglutinin esterase (HE) gene, which encodes a glycoprotein with neuraminate $\mathrm{O}$-acetyl-esterase activity and the active site FGDS, is present downstream to ORF1ab and upstream to $\mathrm{S}$ gene (Figure 1).

68. Vijgen, L., Keyaerts, E., Lemey, P., Maes, P., Van Reeth, K., Nauwynck, H., Pensaert, M., \& Van Ranst, M. (2006). Evolutionary history of the closely related group 2 coronaviruses: porcine hemagglutinating encephalomyelitis virus, bovine coronavirus, and human coronavirus OC43. Journal of virology, 80(14), 7270-7274. https://doi.org/10.1128/JVI.02675-05

69. Moutelikova, R, and J Prodelalova. "First Detection and Characterisation of Porcine Hemagglutinating Encephalomyelitis Virus in the Czech Republic." Veterinární Medicína, 19 Feb. 2019, www.agriculturejournals.cz/web/vetmed.htm?type=article\&id=95_2018-VETMED

70. Astrid Vabret, Thomas Mourez, Stéphanie Gouarin, Joëlle Petitjean, François Freymuth, An Outbreak of Coronavirus OC43 Respiratory Infection in Normandy, France, Clinical Infectious Diseases, Volume 36, Issue 8, 15 April 2003, Pages 985989, https://doi.org/10.1086/374222

71. Kin, N., Miszczak, F., Lin, W., Gouilh, M. A., Vabret, A., \& EPICOREM Consortium (2015). Genomic Analysis of 15 Human Coronaviruses OC43 (HCoV-OC43s)

Circulating in France from 2001 to 2013 Reveals a High Intra-Specific Diversity with New Recombinant Genotypes. Viruses, 7(5), 2358-2377. https://doi.org/10.3390/v7052358

72. Leghari, R.A., et al. "Full-Length Genome Sequencing Analysis of Avian Infectious Bronchitis Virus Isolate Associated with Nephropathogenic Infection." Poultry Science, Elsevier, 11 Dec. 2019, www.sciencedirect.com/science/article/pii/S0032579119318012.

73. Feng, K., Wang, F., Xue, Y., Zhou, Q., Chen, F., Bi, Y., \& Xie, Q. (2017). Epidemiology and characterization of avian infectious bronchitis virus strains circulating in southern China during the period from 2013-2015. Scientific reports, 7(1), 6576. https://doi.org/10.1038/s41598-017-06987-2

74. Herrewegh, A. A., Smeenk, I., Horzinek, M. C., Rottier, P. J., \& de Groot, R. J. (1998). Feline coronavirus type II strains 79-1683 and 79-1146 originate from a double recombination between feline coronavirus type I and canine coronavirus. Journal of virology, 72(5), 4508-4514. https://doi.org/10.1128/JVI.72.5.4508-4514.1998

75. Le Poder, Sophie. "Feline and Canine Coronaviruses: Common Genetic and Pathobiological Features.” Advances in Virology, Hindawi, 31 July 2011, www.hindawi.com/journals/av/2011/609465/.

76. Stadler, K., Masignani, V., Eickmann, M., Becker, S., Abrignani, S., Klenk, H. D., \& Rappuoli, R. (2003). SARS--beginning to understand a new virus. Nature reviews. Microbiology, 1(3), 209-218. https://doi.org/10.1038/nrmicro775

77. Boniotti, M. B., Papetti, A., Lavazza, A., Alborali, G., Sozzi, E., Chiapponi, C., Faccini, S., Bonilauri, P., Cordioli, P., \& Marthaler, D. (2016). Porcine Epidemic Diarrhea Virus and Discovery of a Recombinant Swine Enteric Coronavirus, Italy. Emerging infectious diseases, 22(1), 83-87. https://doi.org/10.3201/eid2201.150544 